\title{
BMJ Global Health The empirical evidence underpinning the concept and practice of person- centred care for serious illness: a systematic review
}

\author{
Alessandra Giusti (D , , ${ }^{1,2}$ Kennedy Nkhoma (D) , ${ }^{1}$ Ruwayda Petrus, ${ }^{3}$ Inge Petersen, ${ }^{3}$ \\ Liz Gwyther, ${ }^{4}$ Lindsay Farrant, ${ }^{4}$ Sridhar Venkatapuram (D) , ${ }^{2}$ Richard Harding (D) ${ }^{1}$
}

To cite: Giusti A, Nkhoma K, Petrus $\mathrm{R}$, et al. The empirical evidence underpinning the concept and practice of person-centred care for serious illness: a systematic review. BMJ Global Health 2020;5:e003330. doi:10.1136/ bmjgh-2020-003330

Handling editor Seye Abimbola

- Additional material is published online only. To view please visit the journal online (http://dx.doi.org/10.1136/ bmjgh-2020-003330).

Received 6 July 2020 Revised 21 0ctober 2020 Accepted 23 0ctober 2020

Check for updates

(c) Author(s) (or their employer(s)) 2020. Re-use permitted under CC BY. Published by BMJ.

${ }^{1}$ Cicely Saunders Institute of Palliative Care, Policy and Rehabilitation, King's College London, London, UK

${ }^{2}$ King's Global Health Institute, King's College London, London, UK

${ }^{3}$ School of Applied Human Sciences, University of KwaZuluNatal College of Humanities, Durban, South Africa

${ }^{4}$ School of Public Health and Family Medicine, University of Cape Town Faculty of Health Sciences, Cape Town, Western Cape, South Africa

Correspondence to

Alessandra Giusti;

alessandra.giusti@kcl.ac.uk

\section{ABSTRACT}

Introduction Person-centred care has become internationally recognised as a critical attribute of highquality healthcare. However, the concept has been criticised for being poorly theorised and operationalised. Serious illness is especially aligned with the need for person-centredness, usually necessitating involvement of significant others, management of clinical uncertainty, high-quality communication and joint decision-making to deliver care concordant with patient preferences. This review aimed to identify and appraise the empirical evidence underpinning conceptualisations of 'personcentredness' for serious illness.

Methods Search strategy conducted in May 2020. Databases: CINAHL, Embase, PubMed, Ovid Global Health, MEDLINE and PsycINFO. Free text search terms related to (1) person-centredness, (2) serious illness and (3) concept/ practice. Tabulation, textual description and narrative synthesis were performed, and quality appraisal conducted using QualSyst tools. Santana et al's person-centred care model (2018) was used to structure analysis.

Results PRISMA (Preferred Reporting Items for Systematic Reviews and Meta-Analyses) flow data: $n=12,446$ studies screened by title/abstract, $n=144$ full articles assessed for eligibility, $n=18$ studies retained. All studies $(n=18)$ are from high-income countries, and are largely of high quality (median score 0.82 ). The findings suggest that person-centred care encompasses the patient and family being respected, given complete information, involved in decision-making and supported in their physical, psychological, social and existential needs. The studies highlight the importance of involving and supporting family/friends, promoting continuation of normality and self-identity, and structuring service organisation to enable care continuity.

Conclusion Person-centred healthcare must value the social network of patients, promote quality of life and reform structurally to improve patients' experience interacting with the healthcare system. Staff must be supported to flexibly adapt skills, communication, routines or environments for individual patients. There remains a need for primary data investigating the meaning and practice of PCC in a greater diversity of diagnostic groups and settings, and a need to ground potential components of PCC within broader universal values and ethical theory.

\section{Key questions}

What is already known?

- Person-centred care has become internationally recognised as a dimension of high-quality healthcare promoted as a core competency of health workers, a key component of primary care and essential to achieving the Universal Health Coverage goals.

- Ongoing conceptual debates are attempting to determine what constitutes 'person-centredness' and how this concept can be understood and implemented in a variety of settings.

- Serious illness is especially aligned with the need for PCC; the complex clinical scenarios surrounding serious illness usually necessitate the involvement of significant others and depend on high-quality communication and joint decision-making to deliver care concordant with patient preferences, with recognition and management of clinical uncertainty.

\section{INTRODUCTION}

Person-centred care has become internationally recognised as a dimension of highquality healthcare. ${ }^{1}$ The Institute of Medicine describes quality care as that which is: "safe, effective, patient-centred, efficient, timely and equitable". ${ }^{2}$ WHO policy on people-centred healthcare highlights person-centredness as a core competency of health workers, a key component of primary care, and essential to achieving the Universal Health Coverage goals. ${ }^{3-6}$

A variety of terms have been used to denote person-centred approaches. 'Patientcentredness' was first to gain prominence and aimed to challenge the reductionism of the biomedical model and stress the importance of psychosocial factors. ${ }^{23}$ Many moved towards use of the term 'person-centredness', suggesting this better articulates the holism of the 'whole person' and a broader conception of well-being. ${ }^{78}$ In recent years, the term 


\section{Key questions}

\section{What are the new findings?}

- Included studies largely support the Santana et al model of PCC and suggest that additional domains should be given visibility: family and friend involvement and support; promoting continuation of normality and self-identity; structuring service organisation to enable continuity of care and patient navigation.

- The empirical data stresses the importance of patients and families being respected, listened to, understood, given honest, complete and comprehendible information and being engaged in all decisions that affect their daily life, care and treatment. Patients must be supported in their physical, psychological, social and spiritual needs.

- All retained studies were conducted in high-income, Western countries.

- Empirical studies present invaluable data on the meaning and practice of PCC, however none develop this evidence into a theorised framework for implementation of PCC for serious illnesses.

\section{What do the new findings imply?}

- Person-centred healthcare must value the social network of each patient, promote quality of life and personal goals not only health status improvement, and implement structural reforms to improve patients' experience of interacting with the healthcare system.

- Health systems must be structured to enable sufficient availability and accessibility of health workers, and support staff to be able and willing to flexibly adapt skills, communication, routines or environments for individual patients.

- There is a need for primary data investigating the meaning and practice of PCC in a greater diversity of diagnostic groups and settings, particularly non-Western, low- and middle-income settings.

- There is a need to consider the theoretical underpinnings of PCC and to ground potential components within broader universal values and ethical theory.

'people-centredness' has also gained prominence, emphasising a focus on "the whole person in their specific familial and community contexts". ${ }^{9}$ Person-centred, patient-centred and people-centred care (PCC) all embody an approach that consciously adopts the perspectives of individuals, families and communities, respects and responds to their needs, values and preferences and sees them as participants in their own healthcare rather than just beneficiaries. ${ }^{2}{ }^{10}$

Conceptual clarity is critical to the design, delivery and replication of successful innovations in care. ${ }^{11}$ Despite the global prominence of PCC as a goal of health systems, the approach suffers from a lack of clarity. Ongoing conceptual debates are attempting to determine what constitutes 'person-centredness' and how this concept can be understood and applied in a variety of contexts. ${ }^{72-14}$ While numerous conceptualisations of PCC are presented in existing literature, ${ }^{815-21}$ most do not appear to offer empirical origins or practical guidance on the implementation of PCC. The WHO Global strategy on peoplecentred and integrated health services recognises that there is not a single model of PCC to be proposed, but rather that it should be context-specific and that each country should generate its own evidence to enable appropriate, acceptable, feasible practice of PCC. ${ }^{10}$ It is currently unclear what evidence is available to model contextuallyappropriate and culturally-appropriate PCC.

The need for a person-centred approach is particularly important in the context of serious illness. The complex clinical scenarios surrounding serious illness usually necessitate the involvement of significant others, high-quality communication and joint decision-making to deliver care concordant with patient preferences, with recognition and management of clinical uncertainty. ${ }^{22-24}$ As populations age, as infectious disease is better managed, and multimorbidity becomes more prevalent, serious health-related suffering associated with conditions such as cancer, chronic lung disease and dementia is rising fastest in low- and middle-income countries (LMICs) ${ }^{25}$ Serious illness is also a context in which delivering PCC can be more complex and may require more dimensions to a greater degree than for non-serious illness. Focussing specifically on serious illness is therefore a means of 'stress testing' generalist PCC theory and ensuring it captures 'what matters' in all diagnostic cases. A better understanding of PCC in the context of serious illness would have health-system-wide relevance for other less complex clinical scenarios.

This systematic review aims to aggregate and appraise the empirical evidence underpinning the concept and practice of PCC in the context of serious illness. Specifically, the objectives of the review are to answer the following questions:

1. What is the primary data underpinning conceptualisations and practice-based frameworks of "personcentredness' in the context of serious illness?

2. What is the quality of this data?

3. What are the key constructs of PCC according to this data?

\section{METHODS}

This systematic review follows the Preferred Reporting Items for Systematic Reviews and Meta-Analyses (PRISMA) recommendations. ${ }^{26}$ The review protocol was registered prospectively with PROSPERO: https://www.crd.york. ac.uk/prospero/display_record.php?RecordID=139259 (registration number 139259).

\section{Definition of terms}

To structure this review, literature was considered in line with two frequently cited definitions of PCC, one policy-led (using the term 'people-centredness') and one patient-led (using the term 'patient-centredness'):

1. "An approach to care that consciously adopts the perspectives of individuals, families and communities and sees them as participants as well as beneficiaries of trusted health systems that respond to their needs and preferences in humane and holistic ways." (WHO, $2015)^{10}$

2. "Care that is focussed and organised around people, rather than disease. Within this approach disease prevention and management are important but 
not enough to address the needs of person, family and community." (International Alliance of Patients Organisations, 2007) ${ }^{27}$

These definitions informed the broad review search strategy.

Numerous terms exist relating to person-centred care, including patient-centred, people-centred, patientdirected and so forth. We acknowledge that these various terms have differences in their origins and connotations. ${ }^{28}$ However, as they overlap significantly and are often used interchangeably we chose to include all terms in the search strategy and analysis. When referring to this approach we chose to use the term 'person-centred'. In agreement with Ekman $e t a l^{8}$ and The Health Foundation, ${ }^{29}$ we take that view that the word 'person' avoids reducing the individual to a mere recipient of services and better highlights the whole human being with reason, preferences, needs and a social and cultural background.

The review focuses on serious illnesses in line with the following definition: "Serious illness carries a high risk of mortality, negatively impacts quality of life and daily function, and/or is burdensome in symptoms, treatments or caregiver stress. This includes conditions not advanced or high dependency/low function that carry a degree of clinical uncertainty" (Kelley et al, 2016). ${ }^{30}$

According to Kelley et al's broadest definition of serious illness, serious medical conditions include: cancer (metastatic or hematological), renal failure, dementia, advanced liver disease or cirrhosis, diabetes with severe complications, amyotrophic lateral sclerosis, acquired immune deficiency syndrome, hip fracture, chronic obstructive pulmonary disease or interstitial lung disease if using home oxygen or hospitalised, and congestive heart failure if hospitalised for the condition. ${ }^{30}$

\section{Search strategy}

The full search strategy is reported in online supplemental appendix A. The following databases were searched on 18 May 2020 with no date restrictions: Cumulative Index to Nursing and Allied Health Literature (CINAHL), Embase, MEDLINE, Ovid Global Health, PsycINFO and PubMed. Forward and backward reference chaining of included articles was performed.

We included free text search terms (title, abstract and keyword search) related to (1) person-centred care/ patient-centred care, (2) serious illness and (3) concept or practice (the meaning of PCC or way in which PCC is enacted). Search terms were adapted to each database subject headings and 'exploded' terms. The specific serious conditions included were those listed by Kelley et $a l^{30}$ within their broad, operationalised definition of serious illness. Please see online supplemental appendix A for full list of search terms and example search strategy.

\section{Data collection and extraction}

All potential references identified were exported to EndNote reference manager and deduplicated. The primary reviewer (AG) assessed the titles and abstracts against the inclusion and exclusion criteria (detailed in online supplemental appendix A). The full texts of remaining references were then similarly screened. Any reference for which inclusion was unclear was agreed through discussion with the secondary reviewer $(\mathrm{KN})$ or adjudicated by a third reviewer (RH) if consensus was not reached. The following variables were extracted from retained studies into a common table: authors, year of publication, country, setting, aim and objectives, study design and methods, sample and main findings.

\section{Quality assessment}

We applied Kmet et als Standard Quality Criteria ${ }^{31}$ to the primary data. The checklists (quantitative data $\mathrm{n}=14$-items, qualitative data 10-items) score each criterion 'yes' $=2$, 'partial' $=1$ and 'no' $=0$. Items deemed not applicable are excluded from the summary score, which ranges from 1 (highest) to 0 (lowest). Online supplemental appendix A further details the method to calculate scores. We did not exclude studies based on quality score. The primary reviewer (AG) assessed the quality of each study. The secondary reviewer $(\mathrm{KN})$ also assessed the quality of $n=5$ of the studies and met with the primary reviewer thereafter to compare assessments, resolve any discrepancies and enable reflections to be applied to all other studies' quality assessments.

For quantitative studies, Kmet et al propose a cut-off score of 0.75 as the threshold for including a paper in a review. ${ }^{31}$ As our goal was to assess data quality rather than exclude data failing to meet a quality threshold, we used Lee $e t a l \mathrm{~s}^{32}$ definitions for Kmet $e t a l$ s quality scores; strong (summary score of $>0.80$ ), good (summary score of 0.71 to 0.79 ), adequate (summary score of 0.50 to 0.70 ) and limited (summary score of $<0.50$ ). For qualitative studies, Kmet et al use a threshold of 0.55 for inclusion of a study into their systematic review, ${ }^{31}$ therefore we defined qualitative papers with scores of $\geq 0.55$ as 'adequate quality' and $\leq 0.54$ as 'low quality'.

\section{Data analysis}

Retained studies were analysed using narrative synthesis in line with Guidance on the Conduct of Narrative Synthesis in Systematic reviews. ${ }^{33}$ The preliminary synthesis was performed by tabulation, grouping and clustering.

To synthesise the extracted data the authors adopted a PCC model developed by Santana and colleagues ${ }^{34}$ (hereafter referred to as Santana model). The Santana model was selected to structure the analysis of retained studies as it provides comprehensive, practical guidance for implementation of PCC, explicitly linking this guidance to the Donabedian model for assessing healthcare quality. ${ }^{35}$ Santana et al's model was generated through a narrative review and synthesis of evidence, recommendations and best practice from implementation case studies, as well as existing frameworks. However, besides the consultation of a patient representative, there is limited voice of patients and families informing the model. The model's authors suggest validation of the framework with 


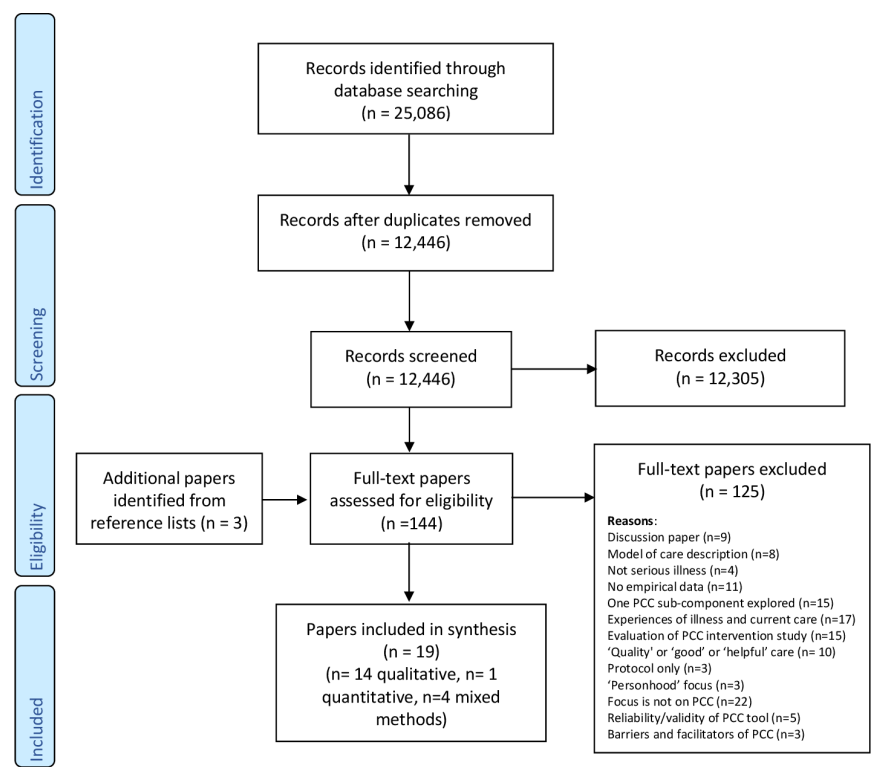

Figure 1 PRISMA (Preferred Reporting Items for Systematic Reviews and Meta-Analyses) 2009 flow diagram.

additional diverse patient perspectives and to identify any necessary revisions or additions. ${ }^{34}$

The components of the Santana model were used to construct an a priori coding frame for deductive analysis of the study findings retained in this systematic review (see online supplemental figure 1 for a priori coding frame). Findings that did not fit into the a priori frame were inductively coded into new codes. The primary reviewer (AG) coded the data using NVivo V.12 software, coding data that did not fit into the a priori frame into additional 'Other' nodes. The primary reviewer reviewed the contents of these 'Other' nodes throughout the analysis, generating new inductive codes where new themes appeared and revising or adding to these as more data was coded. New inductive codes were reviewed by the second and third reviewers $(\mathrm{KN}$ and $\mathrm{RH}$ ), and discussed until consensus on new code meanings and labels was reached.

\section{Patient and public involvement}

Patient and public involvement was not conducted as part of this review.

\section{RESULTS}

The search summary flowchart following PRISMA guidelines is presented in figure 1 . The search yielded 12,446 references following deduplication, and 18 studies $/ \mathrm{n}=19$ papers $^{36-54}$ were retained and synthesised in this review. The characteristics of included studies are summarised in box 1. Further detailed characteristics of each included study are presented in online supplemental table 1, with Kmet $e$ t al $\mathrm{s}^{31}$ data quality score.

\section{Synthesis of included studies' findings}

Patient-family-provider relationship

Overall, the findings suggest that PCC encompasses empowerment of both the patient and their family by

\section{Box 1 Characteristics of included studies}

\section{Countries and settings}

All retained studies ( $n=18 / 18$ ) reported data from high-income,

Western countries.

- The Netherlands $(\mathrm{n}=5 / 18)^{36-40}$

- Canada $(\mathrm{n}=3 / 18)^{41-43}$

- Australia $(n=3 / 18)^{44} 4549$

- USA $(\mathrm{n}=2 / 18)^{46} 50$

- UK $(n=1 / 18)^{47}$

- Ireland $(\mathrm{n}=1 / 18)^{53}$

- Norway $(n=1 / 18)^{48}$

- Sweden $(n=1 / 18)^{54}$

- Germany ( $\mathrm{n}=1 / 18$ study reported in $\mathrm{n}=2 / 18$ papers) $)^{51} 52$

Healthcare settings

- Hospital wards $(n=5 / 18)^{37} 38414748$

- Residential aged care facilities $(n=3 / 18)^{444554}$

- Outpatient clinics $(n=2 / 18)^{3650}$

- Nursing homes $(\mathrm{n}=1 / 18)^{53}$

- Cancer centre $(n=1 / 18)^{42}$

- Academic cancer institution $(\mathrm{n}=1 / 18)^{43}$

- Unknown/combination ( $n=5 / 18$ studies reported in $n=6 / 19$ papers) $)^{394046495152}$

Diagnostic groups and healthcare professionals

- Cancer $(n=10 / 18 \text { studies reported in } n=11 / 17 \text { papers })^{36383941-4348-52}$

- Dementia $(\mathrm{n}=4 / 18)^{44} 455354$

- End-stage renal disease $(n=1 / 18)^{37}$

- Palliative or end-of-life care $(n=2 / 18)^{40} 46$

- Mixed diagnostic groups experiencing acute care $(n=1 / 18)^{47}$

Participant groups included

- Healthcare professionals ( $n=14 / 18$ studies reported in $n=15 / 18$ papers) ${ }^{37} 39-474951-54$

- Patients $(n=10 / 18)^{36-39} 424448-5054$

- Caregivers $(n=3 / 18)$ studies included ${ }^{42} 4449$

- Volunteers working in palliative care $(n=1 / 18)^{40}$

\section{Study designs}

Qualitative designs $(n=13 / 18)$ :

- Semi-structured interviews ( $n=11 / 18$ studies reported in $n=12 / 19$ papers) ${ }^{36} 38$ 43-49 51-53

- Focus groups $(n=2 / 18)^{43} 4750$

- Case studies (interview and observation) $(n=1 / 18)^{41}$

- Mixed qualitative methods (posters and interviews, $n=1 / 18)^{42}$ interviews and focus groups, $(n=1 / 18)^{49}$

Quantitative design $(n=1 / 18)$ :

- Survey $(\mathrm{n}=1 / 18)^{54}$

Mixed-methodology designs $(n=4 / 18)$ :

- $Q$ methodology $(n=2 / 18)^{3740}$

- Questionnaire $(\mathrm{n}=1 / 18)^{38}$

- Delphi method $(n=1 / 18)^{39}$

Term used to refer to the PCC approach

- Patient-centred care $(\mathrm{n}=8 / 18)^{36-40} 48-50$

- Person-centred care $(n=7 / 18)^{42} 444547495354$

- Patient-centred and family-centred care $(n=1 / 18)^{43}$

- Client-centred care $(\mathrm{n}=1 / 18)^{46}$

- Individualised integrative care $(n=1 / 18$ reported in $n=2 / 18$ papers) $)^{5152}$

- Interprofessional patient-centred care $(n=1 / 18)^{41}$

Kmet Data Quality Scores 


\section{Box 1 Continued}

Range $=0.35$ to 0.95 (possible range: 0 to 1 )
Median $=0.82$
Qualitative studies and qualitative component of mixed-methods
studies ( $n=17 / 18$ ):
$n=17$ scored $\geq 0.55$ (adequate quality)
$n=1$ scored $\leq 0.54$ (low quality).
Quantitative studies and quantitative component of mixed-methods
studies ( $n=5 / 18$ ):
$n=4$ scored $>0.80$ (strong)
$n=1$ scored $0.71-0.79$ (good)
Summary of aims and research questions of studies
retained in this review
$n=8 / 18$ studies included an objective to investigate what is un-
derstood by the term PCC or what PCC should consist of in prac-
tice. ${ }^{37} 40$ 42 $44-48$
$n=3 / 18$ studies focused on patients' experiences and expectations
of care in relation to predetermined ideas of PCC components. ${ }^{36} 4950$
$n=2 / 18$ studies aimed to develop PCC indicators. ${ }^{38} 39$
$n=2 / 18$ studies (reported in $n=3 / 17$ papers) aimed to investigate
how teams that identify as providing PCC practice their care. ${ }^{4151} 52$
$n=2 / 18$ studies aimed to investigate clinicians' knowledge and at-
titudes towards PCC. ${ }^{43} 53$
$n=1 / 18$ study aimed to identify the organisational, environmental,
resident and staff variables associated with aged care units with
higher perceived levels of PCC. ${ }^{54}$

being respected, , $^{41485053}$ listened to, ${ }^{36} 374748$ understood, ${ }^{47}$ given honest, complete and comprehendible information ${ }^{36} 3739-41434849$ and by being engaged in treatment decisions and all decisions that affect their daily life and care. ${ }^{36374246485051}$ This requires collaborative, trusting relationships to be developed between patients, families and clinicians, ${ }^{40} 47$ 49-51 which rely on clinicians' communication skills, ${ }^{39} 4349$ attitude ${ }^{41}$ and demonstrable compassion, ${ }^{42}$ for example, by comforting nervous patients. ${ }^{36}$ The studies highlighted specific patient information needs, for example, using diagrams or drawings to aid comprehension, using accessible language, providing information about the possible course of the disease and information about the treatment option of "no active therapy'. ${ }^{38} 49$ It was also raised that patients should be given the necessary information, education and support to enable self-management. ${ }^{39}$

A further dominant theme was the importance of involving and supporting the patient's family, friends or significant others, ${ }^{3644464749}$ although some patients may deem this a lesser priority. ${ }^{37} 40$

In addition to physical symptom control, the studies suggest patients must also be supported in their psychological, social and spiritual needs, ${ }^{39} 4045495152$ with great attention to all needs and aspects of care that are important to the person. ${ }^{36424647}$ Sufficient time ${ }^{5152}$ and availability of staff $^{41}$ was identified as crucial to address these needs. ${ }^{54}$ This also requires flexibility and willingness to adapt skills, routines or environments for individual patients. ${ }^{446}$
Several studies' findings placed weight on promoting autonomy, continuation of self and normality and enabling patients to participate in life. ${ }^{4445} 5253$ This was particularly highlighted in studies focussed on dementia patients and nursing homes, ${ }^{44} 53$ where a dementia-friendly physical environment was also deemed important. ${ }^{54}$

\section{Organisational level requirements}

On an organisational level, PCC was reported to demand a shared philosophy of care, ${ }^{54}$ satisfactory leadership, support from colleagues and continuing education and mentorship of staff. ${ }^{54}$ PCC was seen as requiring interdisciplinary collaboration, ${ }^{5154}$ and consistency and regularity in collaboration of all members of a care team. ${ }^{41}$ Furthermore, all staff (not only front-line) were deemed responsible for providing person-centred care. ${ }^{42}$ Included studies highlighted the importance of the coordination and continuity of patient care ${ }^{449}$ and of streamlining care delivery ${ }^{43}$ for example, by having nursing staff provide additional teaching following the physician visit, ${ }^{43}$ or appointing each patient a care coordinator. ${ }^{37} 3949$ Studies also indicated the importance of enhancing accessibility of healthcare services and considering logistical barriers, such as lack of transport or financial resources. ${ }^{49}$

\section{Complementary findings across participant groups, across countries and across PCC terms}

There were no clear discrepancies between the findings of studies incorporating patient participants, caregiver participants or healthcare professional participants. The heterogeneity of studies did not permit analysis to determine difference between countries or regions. However, the study conducted with indigenous Australian populations reported study-specific findings such as the high financial burden of accessing care and the importance of feeling 'culturally safe' within the healthcare system. ${ }^{49}$ There was also no evidence of consistent differences between findings from studies using different terms within the PCC consortium, that is, patient-centred care, patient-centred and family-centred care, client-centred care and so on. Based on the WHO definition of 'peoplecentredness', we hypothesised that this term has conceptual differences to person-centredness and patientcentredness and wished to investigate what these may be. However, as none of the retained empirical studies used this term we did not have the opportunity to investigate this.

\section{Domains of Santana model supported by included studies' data}

The data from included studies largely supported the Santana model components (online supplemental table 2), providing more detail about the specific meanings of subdomains, and suggesting relationships between concepts. This is particularly the case for many of the model's Process dimensions which saw numerous corresponding data codes, for example, Being responsive to 
Table 1 Santana model domains with no assigned codes from included studies:

\begin{tabular}{|c|c|}
\hline & $\begin{array}{l}\text { "S1a. Core values and Philosophy of the organisation" subdomains: } \\
\text { "Vision and mission" } \\
\text { "Patient and healthcare provider rights" } \\
\text { "S1b. Establishing operational definition of PCC" subdomains: } \\
\text { "Consistent operational definitions" } \\
\text { "Common language around PCC" } \\
\text { "S2. Co-designing the development and implementation of educational programs" subdomains: } \\
\text { "Standardised PCC training in all healthcare professional programs" } \\
\text { "Professional education and accrediting bodies" } \\
\text { "S3. Co-designing the development and implementation of health promotion and prevention programs" and all } \\
\text { "S4a. Ensure resources for staff to practice PCC" and subdomain: } \\
\text { "Provide adequate incentives in payment programs; celebrate small wins and victories" } \\
\text { "S5. Providing a supportive and accommodating PCC environment" subdomains: } \\
\text { "Collaborate with and empower patients and staff in designing healthcare facilities" } \\
\text { "Facility that prioritise the safety and security of its patients and staff" } \\
\text { "Spiritual and religious spaces" } \\
\text { "Patient-directed visiting hours" } \\
\text { "S6. Developing and integrating structures to support health information technology" and all subdomains } \\
\text { "S7. Creating structures to measure and monitor PCC" and subdomain: "Co-design and develop framework for } \\
\text { measurement, monitoring and evaluation" }\end{array}$ \\
\hline Process & "P2b. Providing resources" \\
\hline Outcome & $\begin{array}{l}\text { "O2b Patient-Reported Experiences (PREMs)" and subdomain: "Recommendation or rating of hospital, } \\
\text { healthcare provider" } \\
\text { "O2c. Patient-Reported Adverse Outcomes (PRAOs)" and subdomains: } \\
\text { "New or worsening symptoms" } \\
\text { "Unanticipated visits to healthcare facilities" }\end{array}$ \\
\hline
\end{tabular}

preferences, needs and values; Sensitivity to emotional or psychosocial needs; Sharing information; Shared decision-making.

Understanding patient within his or her unique psychosocial or cultural context is an example of a Santana model domain that is better specified through the included studies' findings. Findings related to this domain suggest that clinicians should show interest in the person as a whole and gain an understanding of their psychological and emotional health, spiritual and existential issues, living conditions, financial situation, social support system, culture, personal identity and daily routines and activities. This knowledge should then be translated into tailored care, perhaps providing emotional support from nurses, referring to appropriate specialists, considering patient convenience and resource availability when ordering investigations and initiating conversations and activities that may be meaningful to a particular patient. $^{36383942-47495152}$

\section{Domains of Santana model left unpopulated by included studies' data}

Table 1 presents domains of the Santana model for which no corresponding study data was found. Predominantly, the Structure components of the Santana model were unpopulated by findings from the 16 studies. This includes domains such as "S3. Co-designing the development and implementation of health promotion and prevention programs", and "Spiritual and religious spaces". "P2b. Providing resources" was the only Process domain to be left unpopulated by the data. Outcome dimensions "O2b Patient-Reported Experiences (PREMs)" and "O2c. Patient-Reported Adverse Outcomes (PRAOs)" were left with no corresponding findings from included studies.

\section{Model adaptation: evidence additional to Santana model domains}

Additional units of meaning arose from the included studies that are currently lacking in the Santana model: Family and friend involvement and support, Promoting continuation of normality and self-identity and Structuring service organisation to enable continuity of care and patient navigation. Table 2 presents these inductively-identified additional themes with examples of corresponding codes from supporting studies. Table 3 presents an adapted version of the Santana framework incorporating these additional themes.

Specifically, Family and friend involvement and support was described as: inviting the patient to bring someone to appointments, ${ }^{39}$ establishing conversation with family/ friends ${ }^{42}$ involving family/friends in information-sharing and decisions regarding the patient's care; ${ }^{37}$ providing family/friends with opportunities to ask specialists and nurses questions; ${ }^{38}$ respecting the opinions and worries of friends/family; ${ }^{36}$ acknowledging family/friends in their role as carer for the patient; ${ }^{37} 44$ and involving family/friends at all stages including long-term care, treatment and follow-up. ${ }^{38}$ Being involved was deemed to 


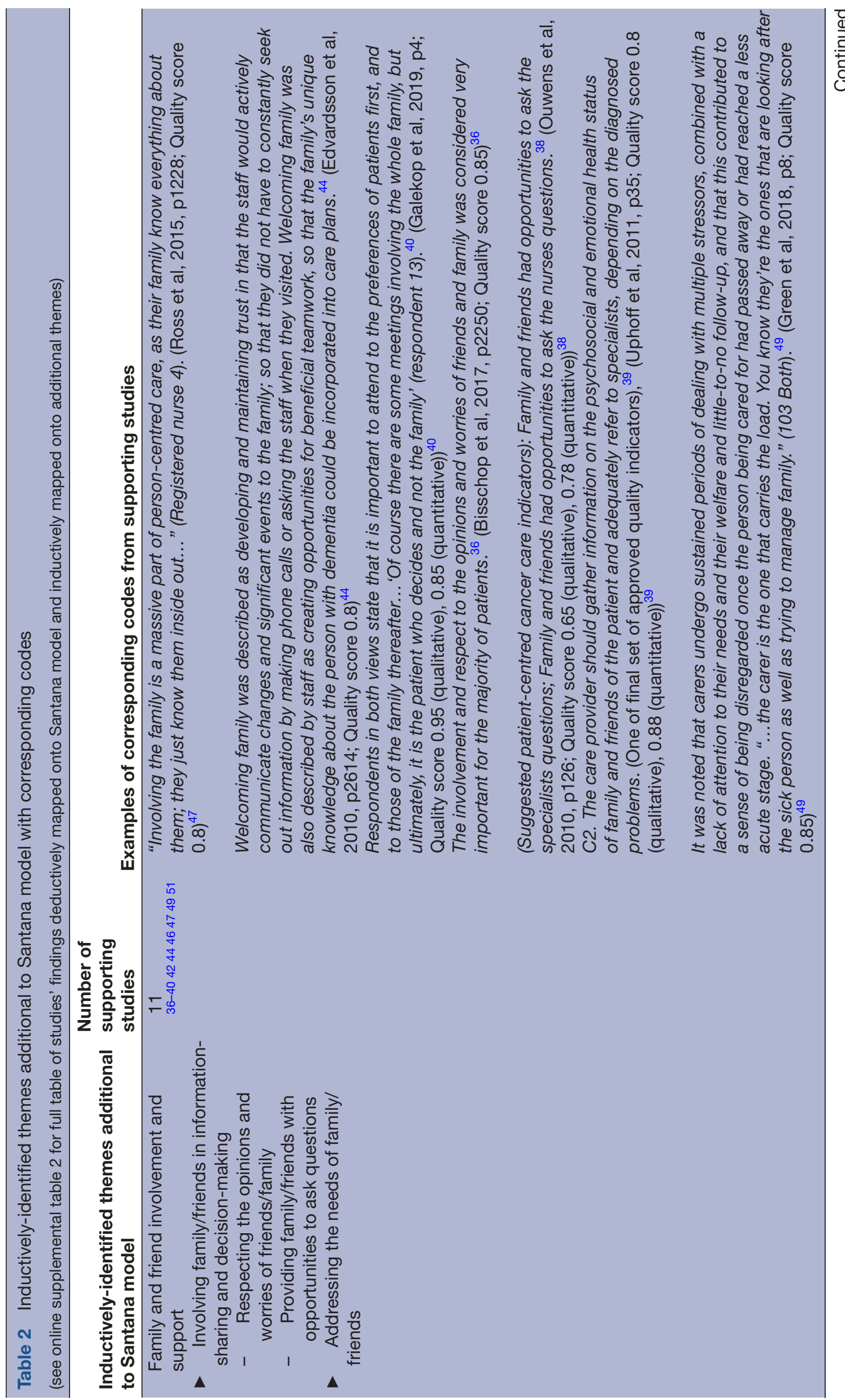




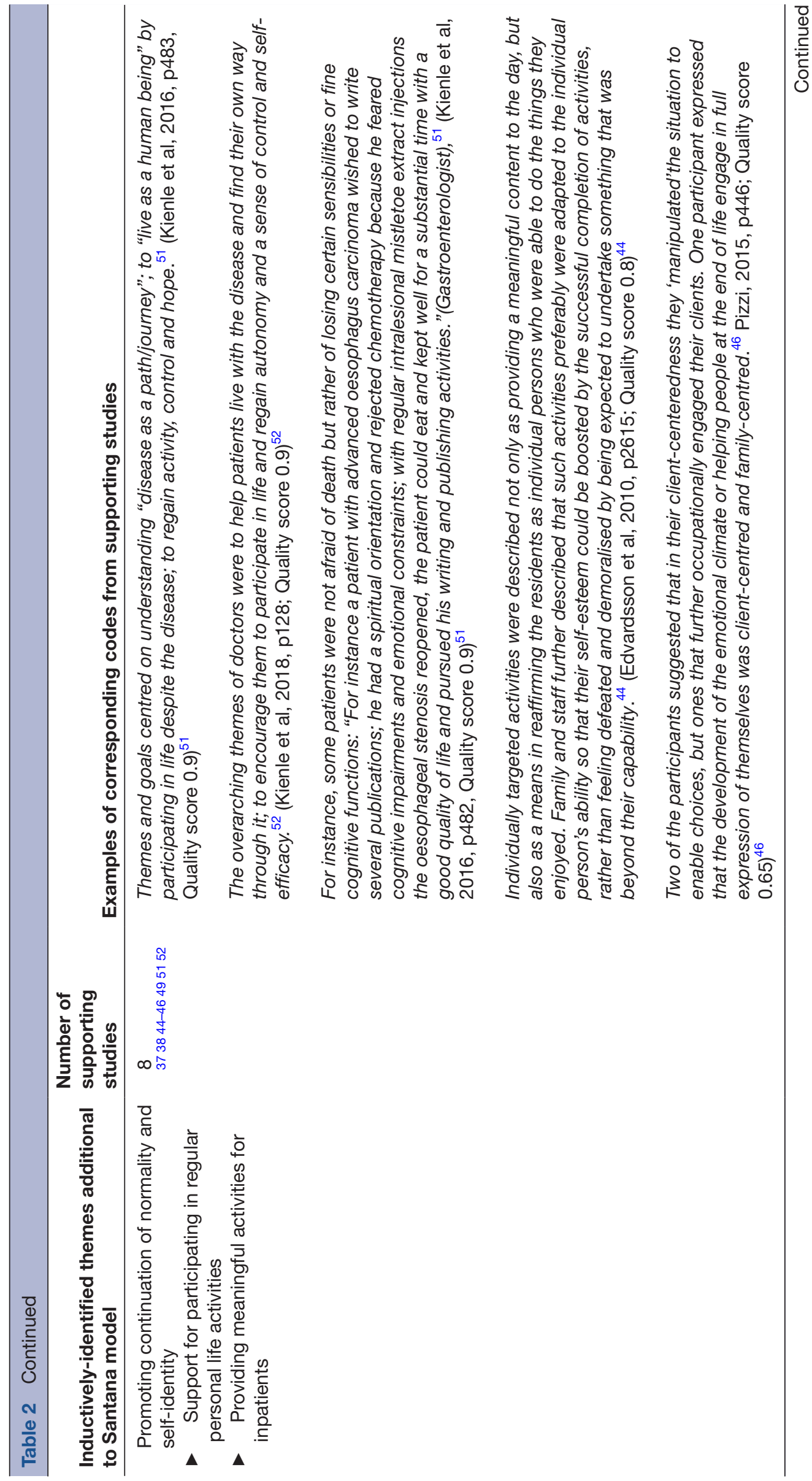




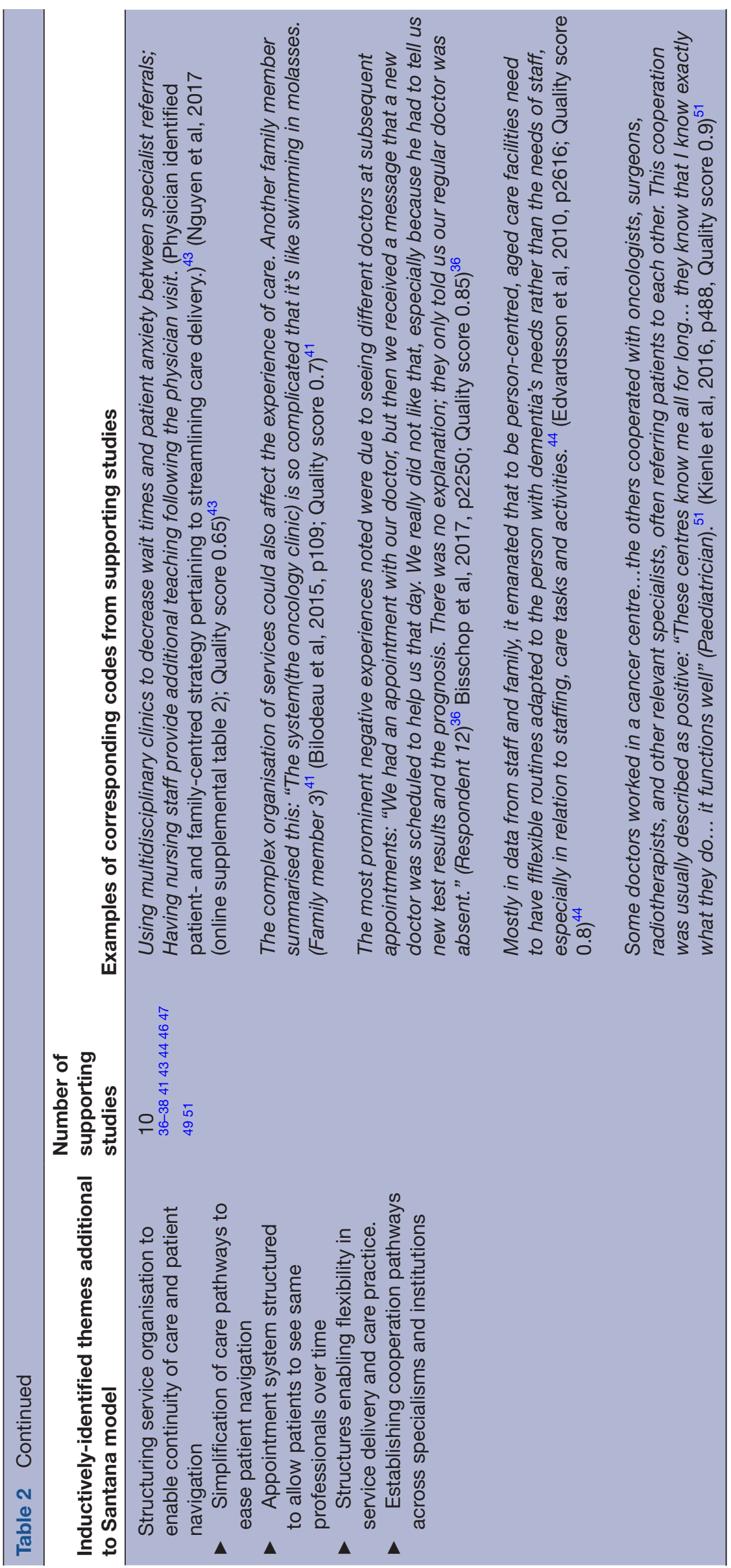




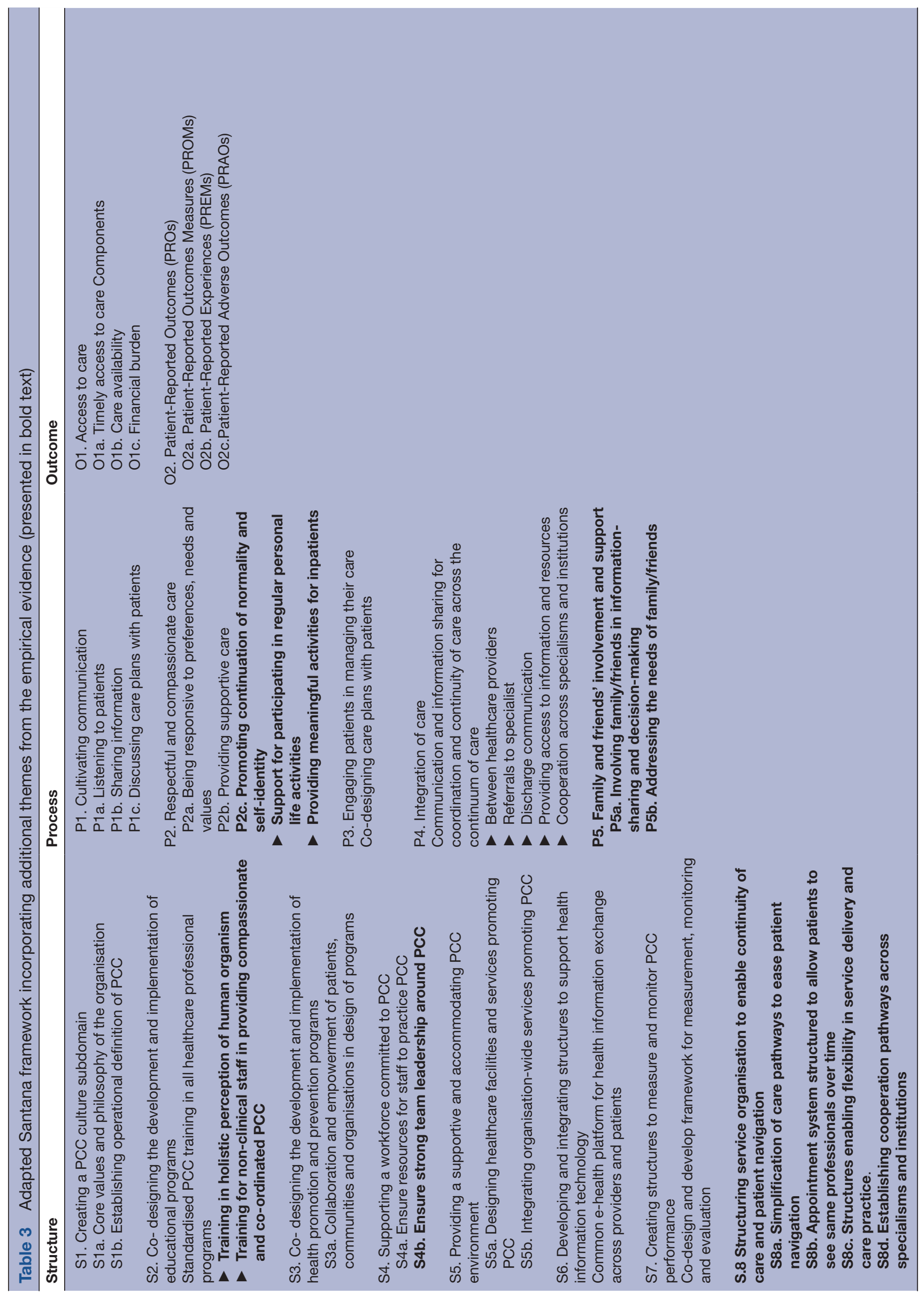


avoid feelings of anxiety among family ${ }^{44} 49$ and aid the patient emotionally, practically and in understanding and reflecting on information provided by clinicians. ${ }^{491}$ This domain of PCC also requires healthcare professionals to pay attention to the needs of family/friends of the patient, ${ }^{374649}$ including providing accommodations in or near the hospital during treatment if possible, ${ }^{37} 49$ and gathering information on the emotional health of family/ friends and referring to specialists as appropriate ${ }^{39}$ It is worth noting that some patients and professionals may place this need as a low priority compared with other PCC domains. ${ }^{37} 40$

Promoting continuation of normality and selfidentity was discussed as requiring encouragement and enablement of persons with serious illness to participate in life despite the disease, and to regain a sense of control and self-efficacy. ${ }^{51}{ }^{52}$ This requires the clinician to consider a patient's life goals and self-identity when discussing care and treatment options. ${ }^{51}$ For long-term inpatients, particularly those with dementia, arranging and enabling meaningful activities was also viewed as a critical part of PCC. Creating individually targeted activities were described not only as providing a meaningful content to the day, but also as a means in reaffirming the residents as individual persons who were able to do the things they enjoyed. ${ }^{44}$

Structuring service organisation to enable continuity of care and patient navigation encapsulates a collection of studies' findings highlighting the importance of streamlining and easing patient navigation, ensuring continuity of care and simplifying the process of multi-specialist care. Suggestions for enabling this included appointing each patient a care coordinator or liaison officer, ${ }^{3741} 49$ ensuring patients see the same professionals over time $e^{364144}$ using multidisciplinary clinics to decrease wait times and patient anxiety between specialist referrals, ${ }^{43}$ and arranging for nursing staff to provide additional information or education following a physician visit. ${ }^{43}$

\section{DISCUSSION}

This review has revealed that a number of different constructs underpin the meaning and practice of PCC in the research evidence. These include patient and family empowerment and autonomy through respectful communication, appropriate information sharing and shared decision-making, addressing psychological, social, spiritual and cultural needs and enhancing coordination and continuity of care. The findings of this review indicate that person-centred healthcare must value the social network of each patient, and should promote quality of life and personal goals, not only health status improvement. This implies that person-centred health systems should be structured with flexible health workforce capacity and support staff to adapt skills, communication, routines or environments for individual patients and their families.
The studies' findings largely validate the domains of the Santana framework of PCC, supporting their importance and providing more detail about specific meanings and subcomponents. The empirical findings of included studies also highlight new PCC themes additional to the Santana model. In focussing on serious illness, this review provides insights into the meaning of PCC that other, less severe conditions may not draw attention to.

The additional theme from included studies' findings: Family and friend involvement and support, is in line with several other prominent conceptualisations of PCC. ${ }^{2} 1655$ It particularly aligns with conceptualisations that focus on 'people-centred' care, such as that by the WHO, bringing attention to the health of people within their full social circles and communities. ${ }^{567}$ The vast majority of everyday care is often undertaken by patient's families and social networks. Enabling families and friends to be active participants in a patient's healthcare should therefore rightly be a key goal of person-centred health systems reform.

Included studies also indicate PCC as enabling patients to continue to participate in daily life and meaningful activities, promoting continuation of self, personal identity and normality. This finding emphasises that patients' highly value quality of life and continuation of their normal lives, not only health status improvement. This supports the idea that PCC involves striving to avoid damage to personal identities that the person values, ${ }^{58}$ and ties into findings from research with frail populations showing patients value care that supports 'getting back to normal' or 'finding a new normal'. ${ }^{59}$ This finding also overlaps with a dimension of Mead and Bower's patientcentredness framework: the 'patient-as-person', which places focus on the individual's experience of illness and the impact of illness on the individual's life or sense of self. $^{15}$

The third additional theme: Structuring service organisation to enable continuity of care and patient navigation, places particular weight on the organisational and structural reforms that are needed to enable person-centred, care-continuity processes. It highlights that PCC requires not only aspects of the clinician-patient interaction to reform, but also the experience the patient has in interacting with the wider healthcare system. Continuity of care has been presented within other prominent conceptualisations of PCC ${ }^{17} 17185555$ however the specific structural features needed to enable this are rarely discussed. This review's findings point towards some practical steps for achieving this, such as appointing each patient a care coordinator or arranging for nursing staff to provide additional teaching following a physician visit.

\section{Strengths and limitations}

The literature search conducted was comprehensive, considered numerous synonyms for PCC and involved no country or year of publication restrictions. This review also benefitted from interdisciplinary, multinational co-authors, allowing a range of perspectives and 
cultural viewpoints to inform the analysis and discussion. However, the review does suffer some limitations. First, only peer-reviewed studies published in English were included. Second, the review research questions and search strategy relating to 'practice' may have contributed to the lack of supporting data for structure and outcome domains of the Santana model. Third, only publications that included the term 'person-centred' (or synonym) were included. Research has certainly been conducted in non-Western LMICs that could inform models of PCC, for example, studies investigating 'good communication skills' or 'empathetic care'. However, searching terms related to, in addition to near synonyms of, PCC would have deemed this review unfeasible. Our aim was to understand PCC as it is currently described.

\section{CONCLUSIONS; IMPLICATIONS FOR PCC RESEARCH, POLICY AND PRACTICE}

This review indicates that there is a stark absence of theoretical models of PCC for serious illness that are grounded in empirical data. Future research should aim to generate theoretically-underpinned empirical frameworks for clinicians and policy makers on how to implement PCC through relevant, appropriate healthcare delivery.

It would also be insightful for future studies to further investigate the aforementioned PCC domains additional to the Satana model to validate whether these domains should constitute PCC components, and if so, what the specific, operationalisable actions within those components should be. One particular additional theme, Involving and supporting the patient's family and friends, unsurprisingly surfaced most clearly in studies that included caregivers as participants $(n=3)$. This highlights the importance of including this participant group in further empirical studies.

The included studies add depth and detail to existing Santana model domains, such as: Understanding patient within his or her unique psychosocial or cultural context. The findings related to this domain recognise that much of health is determined outside the clinic by social situations beyond the patient-clinician interaction, such as education, employment, income, housing, social support and gender. ${ }^{60}$ Acknowledging and addressing these social determinants of health are critical to delivering PCC. Healthcare professionals must be given the support, tools and structures to actively engage with these social determinants of a person's health and illness. However, this finding also raises the wider question of where the responsibility of PCC lies and how much of this rests with the individual clinic and clinician. Certain socially determined aspects of patient health can be positively influenced by a healthcare professional, others cannot. Consideration is needed about how and when clinicians should go beyond the clinic, and how to involve any external actors in contributing towards better patient health outcomes. ${ }^{61}$ We must reflect on how a practice-based theory of PCC should sit within the broader socio-economic and cultural environment in which a health system operates.

Included studies also strongly support Santana model domains revolving around information sharing, shared decision-making and clinicians taking the time to properly understand each patient's needs. This reaffirms the importance of in-depth holistic assessment of the patient and the need to empower patients and families through health literacy, equipping them with the knowledge to make informed decisions. ${ }^{62}$

Several Outcome and Structure components of the Santana model were left unsupported by findings from the studies. This is not to say that those subdomains are unimportant, but that evidence to support them is lacking, and that patients, caregivers and professionals are most immediately exposed to, and concerned with, discussing processes. Future primary research with healthcare managers or policy makers should specify important structural and outcome domains. However, we could also perhaps infer that patients and caregivers facing serious illness are as, or even more, concerned with the quality of processes than with the outcomes which are most often the focus of healthcare improvement efforts. This suggests we should value process improvements as we value outcome improvements and should value the processes of person-centred care in and of themselves rather than just as a means to a series of outcomes. This supports ethical arguments that we should recognise the intrinsic, not just instrumental, value of PCC, and should pursue it as a valued quality and ethical domain in its own right. $^{1358}$

The lack of study findings corresponding to some Structure components of the Santana model may also be a result of the lack of diversity in settings and diagnostic groups of included studies. The components left unpopulated by the studies' findings appear to be those less relevant among the diagnostic groups and highincome settings of included studies. For example, Facility that prioritises the safety and security of its patients and staff is less likely to be voiced as a concern in high-income settings with lower rates of violent crime and civil unrest. Health promotion is an element of PCC that seems less poignant in cases of patients with end-of-life cancer and dementia; this topic may be of greater relevance in other serious conditions that are more responsive to lifestyle factors, such as chronic obstructive pulmonary disease. More empirical work is needed to confirm whether these components are of importance, what these components consist of and how they should be operationalised in day-to-day practice. This empirical investigation would be most insightful if conducted in a diverse range of contexts within which these components are likely to be more relevant.

PCC is an approach that evolved from high-income countries, and African theorists have questioned the relevance of Eurocentric conceptualisations and noted the absence of data to understand the meaning, feasibility and acceptability of PCC in non-Western LMICs. ${ }^{63}$ This is 
unsurprising given existing biasses in healthcare research towards high-income countries, and limited resources and platforms for LMICs to conduct and promote this research. In the context of fewer resources, PCC may also be mistakenly perceived as a 'nice-to-have luxury' rather than a 'need-to-have necessity' and may be challenging to promote in settings with a history of disease-specific, vertical programmes. However, the lack of diversity in study countries raises questions about how both Santana model domains and additional themes could be conceptualised and operationalised globally, in a diversity of settings. Successful enactment of person-centred care would require a multitude of contextual and cultural factors to be considered and accommodated. For example, as Markus and Kitayama ${ }^{64}$ discuss, the dominant construal of self differs between Western and other contexts. Western notions of the 'self' are that of an individual independent agent, while in most non-Western societies the 'individual' is more integrated with significant others. A patient with more interdependent views of self may be highly concerned with harmonising relationships and views. This has very real implications for the clinician-patient interaction and how to best practice involvement and support of a patient's family and wider social network. Data from more individualistic cultures, such as that from the included Galekop et al study, ${ }^{40}$ may suggest that there are some meetings involving the whole family, but ultimately, it is the patient who decides and not the family'. In a more collectivist culture, however, great importance may be placed on collective decision-making and the impacts of illness on a person's network, ${ }^{65}$ and thus, person-centred care would need to enable this. We must carefully consider the underlying values and determinants of culture in order to ensure cultural sensitivity in PCC theory. ${ }^{586}$ A global theory of PCC and resulting policy would need to accommodate different beliefs and worldviews and centre around a common set of human values.

Twitter Kennedy Nkhoma @KennedyNkhoma6 and Sridhar Venkatapuram @sridhartweet

Contributors AG planned, conducted, reported and submitted this systematic review, and is responsible for the overall content as guarantor. KN assessed the quality of a subselection of included studies and compared assessments with $A G$. $\mathrm{KN}$ and $\mathrm{RH}$ reviewed the work as required. RP, IP, LG, LF and SV contributed to design and interpretation. KN, RH, SV, RP, IP, LG and LF approved the manuscript.

Funding This research was partly funded by the National Institute of Health Research (NIHR) Global Health Research Unit on Health System Strengthening in sub-Saharan Africa, King's College London (GHRU 16/136/54) using UK aid from the UK Government to support global health research.

Competing interests None declared.

Patient consent for publication Not required.

Provenance and peer review Not commissioned; externally peer reviewed.

Data availability statement All data relevant to the study are included in the article or uploaded as supplementary information. This paper is a systematic review and does not report novel primary data.

Supplemental material This content has been supplied by the author(s). It has not been vetted by BMJ Publishing Group Limited (BMJ) and may not have been peer-reviewed. Any opinions or recommendations discussed are solely those of the author(s) and are not endorsed by BMJ. BMJ disclaims all liability and responsibility arising from any reliance placed on the content. Where the content includes any translated material, BMJ does not warrant the accuracy and reliability of the translations (including but not limited to local regulations, clinical guidelines, terminology, drug names and drug dosages), and is not responsible for any error and/or omissions arising from translation and adaptation or otherwise.

Open access This is an open access article distributed in accordance with the Creative Commons Attribution 4.0 Unported (CC BY 4.0) license, which permits others to copy, redistribute, remix, transform and build upon this work for any purpose, provided the original work is properly cited, a link to the licence is given, and indication of whether changes were made. See: https://creativecommons.org/ licenses/by/4.0/.

\section{ORCID iDs}

Alessandra Giusti http://orcid.org/0000-0003-2667-1665 Kennedy Nkhoma http://orcid.org/0000-0002-2991-8160 Sridhar Venkatapuram http://orcid.org/0000-0003-3076-0783 Richard Harding http://orcid.org/0000-0001-9653-8689

\section{REFERENCES}

1 Moore L, Britten N, Lydahl D, et al. Barriers and facilitators to the implementation of person-centred care in different healthcare contexts. Scand J Caring Sci 2017;31:662-73.

2 Institute of Medicine Committee on Quality of Health Care in A. Crossing the quality chasm: a new health system for the 21st century. Washington, DC: National Academies Press (US) Copyright 2001 by the National Academy of Sciences, 2001.

3 World Health Organization. People-centred health care: a policy framework. Western Pacific Region: World Health Organization, 2007.

4 World Health Organization, Chronic Diseases and Health Promotion Department. Preparing a health care workforce for the 21st century: the challenge of chronic conditions, 2005.

5 Veillette AMet al. Canadian cancer navigation: an integrative framework. Psycho-Oncology 2009;2:S289-90.

6 World Health Organization and International Bank for Reconstruction and Development/The World Bank. Tracking universal health coverage: 2017 global monitoring report, 2017

7 Mezzich JE, Appleyard J, Botbol M, et al. Ethics in person centered medicine: conceptual place and ongoing developments. International Journal of Person Centered Medicine 2014;3:255-7.

8 Ekman I, Swedberg K, Taft C, et al. Person-centered care--ready for prime time. Eur J Cardiovasc Nurs 2011;10:248-51.

9 World Health Organization. The World Health Report 2008 - Primary Health Care: now more than ever, 2008.

10 World Health Organization. Who global strategy on people-centred and integrated health services: interim report, 2015.

11 Kelly EL, Fenwick KM, Barr N, et al. A systematic review of selfmanagement health care models for individuals with serious mental illnesses. Psychiatr Serv 2014;65:1300-10.

12 Cassell EJ. The person in medicine. Int J Integr Care 2010;10 Suppl:e019.

13 Epstein RM, Street RL. The values and value of patient-centered care. Ann Fam Med 2011;9:100-3.

14 Harding E, Wait S, Scrutton J. The state of play in person-centred care: a pragmatic review of how person-centred care is defined, applied and measured, featuring selected key contributors and case studies across the field. London, 2015: p. 139.

15 Mead N, Bower P. Patient-centredness: a conceptual framework and review of the empirical literature. Soc Sci Med 2000;51:1087-110.

16 Lawrence M, Kinn S. Defining and measuring patient-centred care: an example from a mixed-methods systematic review of the stroke literature. Health Expect 2012;15:295-326.

17 Scholl I, Zill JM, Härter M, et al. An integrative model of patientcenteredness - a systematic review and concept analysis. PLoS One 2014;9:e107828.

18 Britten N, Ekman I, Naldemirci Öncel, et al. Learning from Gothenburg model of person centred healthcare. BMJ 2020;370:m2738.

19 Kitson A, Marshall A, Bassett K, et al. What are the core elements of patient-centred care? A narrative review and synthesis of the literature from health policy, medicine and nursing. $J$ Adv Nurs 2013;69:4-15.

20 Jayadevappa R, Chhatre S. Patient Centered Care - A Conceptual Model and Review of the State of the Art. Open Health Serv Policy J 2011;4:15-25. 
21 Hudon C, Fortin M, Haggerty J, et al. Patient-Centered care in chronic disease management: a thematic analysis of the literature in family medicine. Patient Educ Couns 2012;88:170-6.

22 Fox RC. The evolution of medical uncertainty. Milbank Mem Fund Q Health Soc 1980;58:1-49.

23 McCormick KM. A concept analysis of uncertainty in illness. J Nurs Scholarsh 2002:34:127-31.

24 Mishel MH. Uncertainty in illness. Image J Nurs Sch 1988;20:225-32.

25 Sleeman KE, de Brito M, Etkind S, et al. The escalating global burden of serious health-related suffering: projections to 2060 by world regions, age groups, and health conditions. Lancet Glob Health 2019;7:e883-92.

26 Moher D, Liberati A, Tetzlaff J, et al. Preferred reporting items for systematic reviews and meta-analyses: the PRISMA statement. PLoS Med 2009;6:e1000097.

27 International Alliance of Patients' Organisations. What is patientcentred healthcare? A review of definitions and principles, 2007. Available: http://iapo.org.uk/sites/default/files/files/IAPO\%20PatientCentred\%20Healthcare\%20Review\%202nd\%20edition.pdf [Accessed 17 Sep 2019].

28 Slater L. Person-centredness: a concept analysis. Contemp Nurse 2006;23:135-44.

29 The Health Foundation. Person-centred care made simple; What everyone should know about person-centred care, 2016.

30 Kelley AS, Covinsky KE, Gorges RJ, et al. Identifying older adults with serious illness: a critical step toward improving the value of health care. Health Serv Res 2017;52:113-31.

31 Kmet LM, Lee RC, Cook L. Standard quality assessment criteria for evaluating primary research papers from a variety of fields. Conference proceedings 2004.

32 Lee L, Packer TL, Tang SH, et al. Self-Management education programs for age-related macular degeneration: a systematic review. Australas J Ageing 2008;27:170-6.

33 Popay J, Roberts H, Sowden A, et al. Guidance on the conduct of narrative synthesis in systematic reviews: a product from the ESRC methods programme, 2006

34 Santana MJ, Manalili K, Jolley RJ, et al. How to practice person-centred care: a conceptual framework. Health Expect 2018;21:429-40.

35 Donabedian A. The quality of care. How can it be assessed? JAMA 1988;260:1743-8.

36 Bisschop JAS, Kloosterman FR, van Leijen-Zeelenberg JE, et al. Experiences and preferences of patients visiting a head and neck oncology outpatient clinic: a qualitative study. Eur Arch Otorhinolaryngol 2017;274:2245-52.

37 Cramm JM, Leensvaart L, Berghout M, et al. Exploring views on what is important for patient-centred care in end-stage renal disease using Q methodology. BMC Nephrol 2015;16:74.

38 Ouwens M, Hermens R, Hulscher M, et al. Development of indicators for patient-centred cancer care. Support Care Cancer 2010;18:121-30.

39 Uphoff EPMM, Wennekes L, Punt CJA, et al. Development of generic quality indicators for patient-centered cancer care by using a Rand modified Delphi method. Cancer Nurs 2012;35:29-37.

40 Galekop MMJ, van Dijk HM, van Exel J, et al. Views of professionals and volunteers in palliative care on patient-centred care: a Q-methodology study in the Netherlands. BMC Palliat Care 2019;18:97.

41 Bilodeau K, Dubois S, Pepin J. Interprofessional patient-centred practice in oncology teams: utopia or reality? J Interprof Care 2015;29:106-12.

42 Calisi R, Boyko S, Vendette A, et al. What is person-centred care? A qualitative inquiry into oncology staff and patient and family experience of person-centred care. J Med Imaging Radiat Sci 2016;47:309-14.

43 Nguyen TK, Bauman GS, Watling CJ, et al. Patient- and familycentered care: a qualitative exploration of oncologist perspectives. Support Care Cancer 2017;25:213-9.

44 Edvardsson D, Fetherstonhaugh D, Nay R. Promoting a continuation of self and normality: person-centred care as described by people with dementia, their family members and aged care staff. J Clin Nurs 2010:19:2611-8.

45 Oppert ML, O'Keeffe VJ, Duong D. Knowledge, facilitators and barriers to the practice of person-centred care in aged care workers: a qualitative study. Geriatr Nurs 2018;39:683-8.

46 Pizzi MA. Promoting health and well-being at the end of life through client-centered care. Scand J Occup Ther 2015;22:442-9.

47 Ross H, Tod AM, Clarke A. Understanding and achieving personcentred care: the nurse perspective. J Clin Nurs 2015;24:1223-33.

48 Kvåle K, Bondevik M. What is important for patient centred care? A qualitative study about the perceptions of patients with cancer. Scand J Caring Sci 2008;22:582-9.

49 Green M, Anderson K, Griffiths K, et al. Understanding Indigenous Australians' experiences of cancer care: stakeholders' views on what to measure and how to measure it. BMC Health Serv Res 2018;18:982.

50 Chhatre S, Gallo JJ, Wittink M, et al. Patient-Centred outcomes research: perspectives of patient stakeholders. JRSM Open 2017;8:205427041773851-5.

51 Kienle GS, Mussler M, Fuchs D, et al. Individualized integrative cancer care in Anthroposophic medicine: a qualitative study of the concepts and procedures of expert doctors. Integr Cancer Ther 2016:15:478-94.

52 Kienle GS, Mussler M, Fuchs D, et al. On caring and sharingAddressing psychological, biographical, and spiritual aspects in integrative cancer care: a qualitative interview study on physicians' perspectives. Complement Ther Med 2018;40:126-32.

53 Colomer J, de Vries J. Person-Centred dementia care: a reality check in two nursing homes in Ireland. Dementia 2016;15:1158-70.

54 Sjögren K, Lindkvist M, Sandman P-O, et al. Organisational and environmental characteristics of residential aged care units providing highly person-centred care: a cross sectional study. BMC Nurs 2017;16:44

55 Zill JM, Scholl I, Härter M, et al. Which Dimensions of PatientCenteredness Matter? - Results of a Web-Based Expert Delphi Survey. PLoS One 2015;10:e0141978.

56 World Health Organization,. Framework on integrated, peoplecentred health services. Report by the Secretariat, 2016.

57 Maeseneer J, Weel Cvan, Daeren L, et al. From "patient" to "person" to "people": The need for integrated. People-centered Healthcare 2012;2:601-14

58 Entwistle VA, Watt IS. Treating patients as persons: a capabilities approach to support delivery of person-centered care. Am J Bioeth 2013;13:29-39.

59 Etkind SN, Lovell N, Nicholson CJ, et al. Finding a 'new normal' following acute illness: A qualitative study of influences on frail older people's care preferences. Palliat Med 2019;33:301-11.

$60 \mathrm{CSDH}$. Closing the gap in a generation: health equity through action on the social determinants of health. final report of the Commission on social determinants of health. Geneva: World Health Organization, 2008.

61 Venkatapuram S. Values-Based Practice and Global Health. In: Loughlin M, ed. Debates in Values-based medical practice: arguments for and against. Cambridge: Cambridge University Press, 2014.

62 Lowther K, Harding R, Simms V, et al. Active ingredients of a personcentred intervention for people on HIV treatment: analysis of mixed methods trial data. BMC Infect Dis 2018;18:27.

63 De Man J, Olmen JV, Criel B. Patient-Centered care and peoplecentered health systems in sub-Saharan Africa: why so little of something so badly needed? International Journal of Person Centered Medicine 2016;6:162-73.

64 Markus HR, Kitayama S. Culture and the self: implications for cognition, emotion, and motivation. Psychol Rev 1991;98:224-53.

65 Stanford J, Sandberg DM, Gwyther L, et al. Conversations worth having: the perceived relevance of advance care planning among teachers, hospice staff, and pastors in Knysna, South Africa. J Palliat Med 2013;16:762-7.

66 Setlhare V, Couper I, Wright A. Patient-centredness: meaning and Propriety in the Botswana, African and non-Western contexts. Afr J Prim Health Care Fam Med 2014;6:E1-4. 